\title{
Application of the TPB to Predicting Entrepreneurial Intention of Students: Evidence from Ethiopia
}

\author{
Baymot Tadesse $^{1}$, G. S. Batra ${ }^{2}$ \\ ${ }^{I}$ (Department of Management, Gondar University, Gondar, Ethiopia) \\ ${ }^{2}$ (Department of Management, Punjabi University, Patiala, India)
}

\begin{abstract}
The present study is done with the objective of exploring whether constructs taken from the theory of planned behavior (TPB) influence the entrepreneurial intention of prospective university undergraduates after they graduate. For this purpose, 400 non-business major students were randomly selected from four state universities in Ethiopia (Addis Ababa University, Adama University, Mizan Tepi University, and Debretabor University). 355 valid questionnaires were feed into SPSS version 20.0 and multiple regressions were run. The results reveal that the model explained $51 \%$ of the variation in the dependent variable. Attitude, Perceived behavioral control (PBC), and subjective norm were found to be statistically significant. Attitude explained the highest variation in intention followed by PBC and subjective norm. Moreover, the students' level of intending to start a business after graduation was high. Policy implications, Limitations, and directions for future studies are included.
\end{abstract}

Keywords: entrepreneurship, Ethiopia, intention, TPB, university.

\section{INTRODUCTION}

A few years back, most university graduates were sure to end up getting a decent job in some organizations in Ethiopia. But things are changing faster since then. Vacant positions in organizations are becoming limited to the ever increasing number of university graduates every year. To this end, the pursuit for self-employment is not only an option but it is becoming a necessity. Graduates, however, show little efforts in going through the process of finding their own ventures. This issue is also getting worse due to the attitude of the society regarding the future career options of university graduates.

In Ethiopia, the benefit of education as a tool to train the mind of the students to be innovative and creative is not considered well. Moreover, the community from which the student came presumes college graduates should end up in professional jobs [17]. The university or college students since ever their childhood they were told to hold a degree and become higher professional workers such as scientists and pilots. The idea of coaching children to become entrepreneurs and become their own bosses is very minimal in Ethiopia [17]. The graduates are expected to hold office work in the fields they specialized. If not, considering starting an own small venture is considered low life job. Schools, colleges, and the concerned authorities work very little to change this attitude either [17].

In the Growth and Transformation Plan [18] of Ethiopia, the undergraduate intake capacity of Government higher institutions alone was expected to increase from its baseline scenario 185, 788 in 2009/2010 to 467,000 in 2014/2015. The plan further states that these graduates are vital to assist the achievement of the plan by bridging the gap for the skilled labor force the country needs. This does not mean, however, all graduates hold office jobs. Instead new graduates are expected to employ themselves in jobs created by them. In other words, they are anticipated, and of course, motivated by the government to be entrepreneurs and generate jobs for citizens.

Nevertheless, the entrepreneurial culture is very low among university graduates as university graduates were almost fully employed in both private and public organizations in the past. Currently, however, socio-economic variables are changing so rapidly and hence self-employment is not an option but becoming 
inevitable. To this effect, are prospective undergraduates from government universities ready for this? What factors really influence them to be future entrepreneurs and what impediments deter them from being their own bosses? This is the main query that is to be shaded with light in the current research within the framework of the TPB.

\section{Objective of the study}

The main objective of the present study is to investigate whether constructs taken from "the theory of planned behavior" [2] influence the entrepreneurial intentions of prospective university undergraduates after graduation. The specific objectives of the current research also include the following;

$>$ To investigate if non-business major students have entrepreneurial intentions.

$>$ To investigate if students' attitude toward entrepreneurship affects their intention of forming their own venture.

$>$ To study if perceived behavioral control of the student regarding self-employment affects their entrepreneurship intentions.

$>$ To find out the association between the subjective norm of the society toward entrepreneurship and entrepreneurial intention of the graduates.

\subsection{THE THEORY OF PLANNED BEHAVIOR (TPB)}

The TPB is a modified model that has its roots from the "Theory of Reasoned Action" (TRA). This model is necessitated by the shortfalls of the TRA to deal with the behaviors over which the individual do not have volitional control [4] [9]. Ajzen [2] notes that explaining human behavior is very difficult given its complexity and dynamism. However, it can be studied using two extreme methods which are a psychological process and social institutions.

Having its origin in the works of [4] TRA and further described by [1], the TPB has been applied in testing or experimenting dozens of "volitional behaviors" over the years. To see perspectives farther than the volitional actions, [1] has projected "the TPB" which inculcates an additional predictor-"the Perceived Behavioral Control" of the behavior of interest. [6] Contend that the new antecedent or predictor variable is included hence the behavior to be explained pertains not to action in totality "under volitional governance", but instead to actions related to obstruction both by internal and external factors. The TPB is "parsimonious, well grounded in theory, and robustly predicts a wide variety of planned behaviors" such as new venture creation [13].

\subsection{PREDICTORS OF INTENTION}

The three conceptually independent predictors of intentions are briefed as follows:

Attitude toward the behavior: Attitude is one of the three predictors of Intention in the Theory of Planned Behavior. An attitude represents "a person's general feeling of favorableness or unfavorableness toward some stimulus object" [4]. [9] Also contend that "a person's attitude toward a specific act is proposed to be a function of the act's perceived consequences and of their values to the person". According to the "Theory of Expectancy-Value Model", an individual's overall attitude toward a certain behavior is decided by the subjective values of the outcomes with the behavior and by how strong these associations are [9].

H1: attitude towards entrepreneurship has a strong association with entrepreneurial intention.

Subjective norm: Subjective norm in the Theory of Planned Behavior is a social factor that pertains to the approval or disapproval of the behavior to be pursued [2] [3]. [8] discuss that Subjective norm is postulated to be a function of beliefs and they are about the "normative expectations of salient referent individuals or 
groups". Perceived social pressure is said to enhance to the extent that salient groups with whom a person is motivated to obey are seen as appreciating of the behavior under question.

Many investigators, however, claim that subjective norm doesn't seem to explain the entrepreneurial intention of potential candidates [14]. One problem to measure a social norm is that it varies across culture and also within a culture [7]. For this reason, some researchers tried to reflect the cultural context in subjective norm constructs at least as a proxy measure. Another shortcoming regarding social norm is that "the reference groups" pertaining to the entrepreneurs or potential entrepreneurs are not families and friends only. It might include co-workers and other entrepreneurs as well. This issue is also "context specific" and may vary from country to country.

H2: Subjective norm predicts the entrepreneurial intention of the students.

Perceived Behavioral Control: As noted by [2] perceived behavioral control in the TPB represents one of the determinants of Intention. And it refers to the perceived ease or difficulty of performing the behavior of interest.

According to the Theory of Reasoned action (TRA) [5], Intentions are postulated to capture the motivational factors that affect the intended behavior. They are indications of how much people are determined to exert effort and try to perform the pro-social behavior. As a general rule, the stronger the intention, the more likely should be the performance of the behavior. However, a behavioral intention can properly express behavior only if the behavior under consideration is under "volitional control". In other words, if the individual can decide at will to undertake or not to undertake the behavior [2]. [3] notes the concept of perceived behavioral control was introduced into the theory of planned behavior to embrace the unavoidable nonvolitional essentials, at least potentially, in all behaviors. In line with this [8] also state that the antecedent perceived behavioral control is added to the theory of reasoned action to reflect past experience and possible impediments and obstacles.

H3: perceived behavioral control is strongly associated with the entrepreneurial intention of university students.

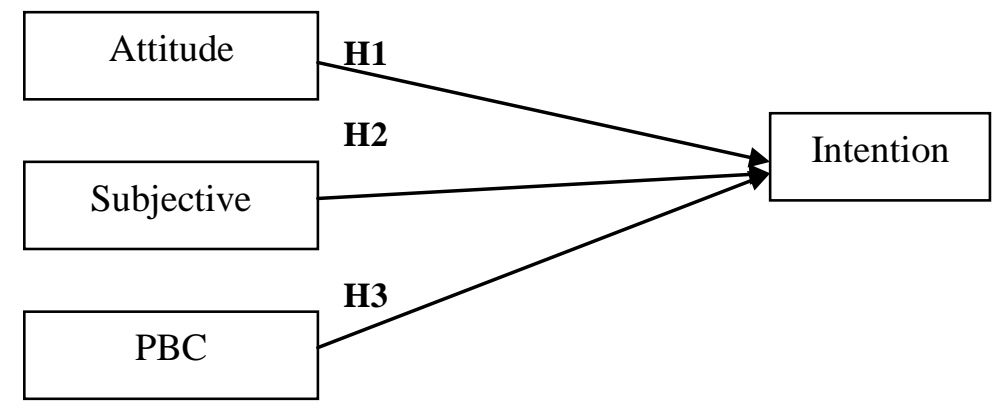

Fig1: Framework of the present study

\section{METHODOLOGY}

The aim of this research is to investigate empirical evidence about the general intention of prospective University undergraduates towards starting their own ventures within one year after graduation. Hence, quantitative research approach is found to be appropriate to capture the intent of the research. As a result, descriptive research design is employed and data was collected using cross-sectional survey at four state universities namely Addis Ababa University, Adama University, Debretabor University, and Mizan Tepi University. 
The Federal Ministry of Education has reported in the academic year 2014/15, the 31 state universities and one college graduated a total of 52,699 students in various types of disciplines in the regular program. Out of this, 41,299 students graduated in non-business major departments (the population for the current study) and the balance is business graduates. Hence taking this figure and adopting the sample size determination formula proposed by [20] with $95 \%$ level of confidence interval and 5\% level of precision, the sample size is determined to be 400 students.

Samples were selected at three stages. At the first stage, four state universities were selected from the 31 state universities and one college in a non-probability fashion. In other words, one university was drawn from each administrative cluster. At the second stage, lists of non-business departments were obtained at all four universities then a systematic random sampling was done to select two departments at each university. And finally at the third stage, the lists of students were collected from each department and samples were drawn in a systematic random sampling technique. Hence, every $\mathrm{n}^{\text {th }}$ observation was selected to take part in the survey. Regarding the decision how many students should be taken from each department, the researcher determined it based on sampling proportional to size. Data was collected over a period of about four weeks from May 22 to June 21, 2015. The Universities were approached by submitting letters written from The Federal Democratic Republic Embassy of Ethiopia in Delhi and from Punjabi University. Totally 400 questionnaires were distributed and collected at the spot. But when the data was encoded into SPSS version 20, it was found out that about 45 were not usable owing to incomplete answers and hence the valid questionnaires are 355.

The major constructs were measured on a five-point Likert scale. The responses range from "strongly agree" to "strongly disagree". Attitude toward the behavior consisted of 5 items, subjective norm 3 items, PBC, 9 items and intention also 9 items. The reliability of instruments was tested and satisfactory results were obtained. Hence, the reliability of constructs in the current research is set in terms of Cronbach $\alpha$ and the points ranged from .07 to 0.8 which corroborates with current literature. The results are; attitude 0.88 , subjective norm 0.7 , $\mathrm{PBC} 0.81$, and intention 0.82 .

\section{RESULTS AND DISCUSSIONS}

Under this section of the article; demographic characteristics of the participants, their entrepreneurial intention level as measured by the dependent variable, and the results of the Multiple Regression Model are discussed.

\subsection{DESCRIPTIVE STATISTICS OF DEMOGRAPHIC CHARACTERISTICS OF THE SUBJECTS}

In the present study of entrepreneurial intention, 355 final year regular undergraduate students took part. Out of which 240 participants or $68 \%$ are male and 115 or $32 \%$ are female students. Regarding the age distribution, the vast majority of the participants or $95 \%$ fall under the age category of $20-25$. The second category, 26-30 comprised 14 students or about $4 \%$ and the rest of the categories $1 \%$. This shows that the age disparity between regular undergraduate students is very minimal. The students were also enquired if they have attended any entrepreneurship course using a "yes" or "no" type of question. 285 students or $80 \%$ reported they did and the rest said "no". Another demographic variable in the current study is the previous business experience of the students. Again a dichotomous type of question was employed to measure this variable. 125 or $35 \%$ of the participating students responded "no" and the balance or $65 \%$ or 230 students reported "yes". Given the age classification of the majority of the students, 20-25, it seems most of them didn't have prior experience in running their own venture. The participants were drawn from multiple departments which were either social or natural sciences. Hence, the data show that 172 were social science students and 183 natural sciences $(48.5 \%$ vs. $51.5 \%)$. 
TABLE I. Participants' gender and age

\begin{tabular}{lccccc}
\cline { 2 - 5 } Gender & no. & $\%$ & Age & no. & $\%$ \\
\hline Male & 240 & 68 & $25-30$ & 338 & 95.2 \\
Female & 115 & 32 & $30-36$ & 14 & 3.9 \\
& & & $31-35$ & 1 & 0.3 \\
& & & $36 \&$ more & 2 & 0.6 \\
Total & 355 & 100 & & 355 & 100 \\
\hline
\end{tabular}

Source: Author's own survey

\subsection{ENTREPRENEURIAL INTENTION OF THE PARTICIPANTS}

As shown in the table below, the students' level of intention toward starting their own business after graduation was measured based on nine items. Accordingly, $30 \%$ of the subjects "strongly agreed" and $38 \%$ agreed" that they will choose entrepreneurship as their future career after graduation. That is, $68.5 \%$ of the participants reveal their agreement (with various levels) to the statement "I will choose a career as an entrepreneur after my graduation". Around $68 \%$ of them also preferred starting own venture than secure paid jobs after graduation. $81 \%$ of the participants were in total agreement when it comes to freedom of finding own business (monetary and time). To be specific, $44.2 \%$ "strongly agreed" and 37\% "agreed" to the item "I want my freedom to express myself in my own business". This result could be an indication that monetary and time freedom as a result of engaging in entrepreneurial activity could be one of the strongest driving forces towards exhibiting a higher level of entrepreneurial intention among university students. Unlike other items, the respondents scored least on the item "I would rather found a company than to be a manager of an existing one" (55\% total agreement). But still their intention to become future entrepreneurs is more than fifty percent. The reason for the least score could be the students somehow needed to secure some sort of experience and seed money before they delve into the business world.

TABLE II. Entrepreneurial intention of the students

\begin{tabular}{lcccccc}
\hline Entrepreneurial & \multicolumn{2}{c}{ percentage $(\%)$} & & & \\
Intention & $* \mathrm{SA}$ & $* \mathrm{~A}$ & $* \mathrm{~N}$ & $* \mathrm{D}$ & $* \mathrm{SD}$ & $* \mathrm{TA}$ \\
\hline $\begin{array}{l}\text {-I will choose a career as } \\
\text { entrepreneur after my graduation }\end{array}$ & 30.1 & 38.3 & 19.4 & 7.6 & 4.5 & 68.4 \\
$\begin{array}{l}\text {-I prefer to be an entrepreneur } \\
\text { rather than to be an employee }\end{array}$ & 33.2 & 34.6 & 17.7 & 7.9 & 6.5 & 67.8 \\
$\begin{array}{l}\text {-I would rather found a company } \\
\text { than to be a manager of an existing }\end{array}$ & 18.6 & 36.6 & 27.0 & 12.4 & 5.6 & 55.2 \\
$\begin{array}{l}\text {-I want the freedom to express } \\
\text { myself in my own business }\end{array}$ & 44.2 & 36.9 & 10.4 & 5.1 & 3.4 & 81.1 \\
$\begin{array}{l}\text {-I would rather be my own boss } \\
\text { than to have a secured job }\end{array}$ & 27.6 & 37.2 & 20.3 & 10.1 & 4.8 & 64.8 \\
-I am ready to do anything to be & 35.5 & 34.9 & 17.7 & 8.5 & 3.4 & 70.4 \\
$\begin{array}{l}\text { entrepreneur } \\
\text {-I will make every effort to start }\end{array}$ & 32.7 & 36.9 & 16.1 & 9.3 & 5.1 & 69.9 \\
\hline
\end{tabular}


IOSR Journal of Business and Management (IOSR-JBM)

e-ISSN: 2278-487X, p-ISSN: 2319-7668

and run my own business

$\begin{array}{lllllll}-\mathrm{I} \text { am determined to create a business } & 27.6 & 39.2 & 18.9 & 9.0 & 5.4 & 66.8\end{array}$

venture

-My professional goal is to be an

$\begin{array}{lllll}27.0 & 33.2 & 20.3 & 13.0 & 6.5\end{array}$

$6.5 \quad 60.2$

entrepreneur

* $\mathrm{SA}=$ strongly agree, $\mathrm{A}=$ agree, $\mathrm{N}=$ neutral, $\mathrm{D}=$ disagree, $\mathrm{SD}=$ strongly disagree, $\mathrm{TA}=$ sum of total agreements.

\subsection{REGRESSION AND CORRELATION ANALYSIS OF THE CONSTRUCTS}

In this part of the analysis, inferential statistics was run and outputs discussed in light of previous empirical findings. First, control variables or demographic variables were included in the model and analysis was run. But since they were found to be insignificant, they were excluded from the model. Therefore, statistically significant independent variables only were considered.

As can be seen from the table below, all the three antecedents were found to be positively correlated with the dependent variable. Attitude has the strongest correlation coefficient $(r=0.620, p<0.01)$ followed by PBC $(r=0.561, p<0.01)$ and the weakest correlation was between subjective norm and intention $(r=0.378, p$ $<0.01$ ). This shows that the attitude of the students toward the intention of starting their own venture after graduation is higher. On the other hand, the pressure from the society or their perception of the approval or disapproval of the community to start their own business [2] is weak. The student's perceived behavioral control is moderated as measured by the correlation coefficient.

TABLE III. Correlation \& descriptive statistics results

\begin{tabular}{|c|c|c|c|c|c|c|c|}
\hline & & 1 & 2 & 3 & 4 & Mean & Std. D \\
\hline 1. & Attitude & 1.00 & & & & 4.03 & 0.77 \\
\hline 2. & S_norm & $.357^{*}$ & 1.00 & & & 3.40 & 0.65 \\
\hline 3. & $\mathrm{PBC}$ & $.405^{*}$ & $.365^{*}$ & 1.00 & & 3.45 & 0.71 \\
\hline & Intention & $.620^{*}$ & $.378^{*}$ & $.561^{*}$ & 1.00 & 3.79 & 0.72 \\
\hline
\end{tabular}

*correlation is significant at the 0.01 level (2-tailed)

The overall model fitness of the current study is $\mathrm{r}^{2}=0.506$ or approximately $51 \%$. This implies that the three predictors of intention (Attitude, perceived behavioral control, and subjective norm) explained $51 \%$ of the variation in the dependent variable. Attitude exerted the highest variation in intention with $\beta=.417$, PBC with $\beta=0.350$ and subjective norm with $\beta$ value 0.101 , indicating the least variation in the dependent variable.

The regression table below reveals that all the three independent variables are statistically significant at $\mathrm{p}<0.01$ and 0.05 levels. Attitude is the highest predictor of intention followed by PBC and then subjective norm (attitude at $\mathrm{P}$-value $=0.000, \mathrm{PBC}$ at $\mathrm{p}$-value $=0.000$ and subjective norm at $\mathrm{p}=0.028$ ). The findings in the current research corroborated with the studies of [15] [19] [12] [10] [16]. They also reported that subjective norm has the least impact on entrepreneurial intention.

TABLE IV. Regression results

\begin{tabular}{lccccc}
\hline & $\beta$ & std. error & Stand. $\beta$ & $\mathrm{t}$ & P-value \\
\hline 1 (constant) & .558 & .182 & & 3.065 & .002 \\
\hline
\end{tabular}

Special Issue - AETM'16 


\begin{tabular}{llllll} 
Attitude & .417 & .039 & .446 & 10.549 & $.000^{*}$ \\
$\mathrm{PBC}$ & .350 & .043 & .347 & 8.181 & $.000^{*}$ \\
$\mathrm{~S} \_n$ norm & .101 & .046 & .092 & 2.205 & $.028^{* *}$ \\
$\mathrm{R}^{2}=.506$ & & & & & \\
Adjusted $\mathrm{R}^{2}=.501$ & & & & & \\
\hline *ignificant at $p<0.01$ level & & & & \\
$* *$ significant at $P<0.05$ level & & &
\end{tabular}

\section{CONCLUSIONS AND RECOMMENDATIONS}

From the results above it can be inferred that undergraduate university students in Ethiopia have a significant level of entrepreneurial intention (they are intending to establish their own venture after graduation).The regression and correlation results also indicate that the three alternative hypotheses are accepted. In other words; attitude, $\mathrm{PBC}$, and subjective norm have predicted the entrepreneurial intention of the university students in Ethiopia. The results further reveal that attitude is the most powerful predictor of intention and subjective norm the weakest.

The implications of the findings to revise the entrepreneurial course nature and deliveries in the public universities are paramount. The entrepreneurship course contents of the universities mainly focus on skill development of the students such as SWOT analysis and business plan writing. The behavioral contents of the course seem to be overlooked. But like any other planned social behavior, entrepreneurial behaviors of the students can also be predicted with the intention [2]. Hence, the concerned curriculum experts need to incorporate behavioral dimensions into the course contents of entrepreneurship. In Ethiopia, as a tradition different stakeholders provide entrepreneurial training to last year undergraduates before the students leave their respective universities and join the labor market. Although this intervention is appreciable, the training need to focus on enhancing the attitude and confidence of the students as these to constructs are the major predictors of entrepreneurial intention.

It's also important to mention the major limitations in the present research. There are a couple of shortcomings that need to be overcome in future researches. First, data was collected in a cross section fashion or in a one-shot process. Second, the actual behavior of the students was not measured as this requires following the students over a long period of time. And finally, the population doesn't incorporate students from private universities and colleges. Therefore, similar future studies in the Ethiopian context shall focus to address the gray areas pinpointed above.

\section{REFERENCES}

[1] I. Ajzen, "From intentions to actions: A theory of planned behavior", Heidelberg, Germany: Springer, $1985,11-39$.

[2] I. Ajzen, "The theory of planned behavior", Organizational Behavior and Human Decision Processes, 50(2), 1991, $179-211$.

[3] I. Ajzen, "Laws of human behavior: Symmetry, compatibility, and attitude- behavior correspondence", Aachen, Germany: Shaker Verlag, 2005, 3-19.

[4] I. Ajzen and M. Fishbein, Understanding attitudes and predicting social behavior (Englewood Cliffs, NJ: Prentice-Hall, 1980).

[5] I. Ajzen and T. J. Madden, "Prediction of goal-directed behavior: Attitudes, intentions, and perceived behavioral control", Journal of Experimental Social Psychology, 22, 1986, 453-474.

[6] R.P. Bagozzi, "The self-regulation of attitudes, intentions, and behavior”, Social Psychology Quarterly, 55(2), $1992,178-204$.

[7] P. Davidsson and J. Wiklund, "Values, beliefs and regional variations in new firm formation rates", Journal of Economic Psychology, 18, 1997, 179-199.

[8] J. Doll and I. Ajzen, "Accessibility and stability of predictors in the theory of planned behavior", Journal of Personality and Social Psychology, 63, 1992, 754-765.

[9] M. Fishbein and I. Ajzen, "Belief, attitude, intention, and behavior: An introduction to theory and research", (Reading, MA: AddisonWesley, 1975). 
IOSR Journal of Business and Management (IOSR-JBM)

e-ISSN: 2278-487X, p-ISSN: 2319-7668

[10] G. Gurbuz and S. Ayikol, "Entrepreneurial Intentions of Young Educated Public in Turkey”, Journal of Global Strategic Management, 4, 2008, $47-56$.

[11] International Monitory Report, “The Federal democratic Republic of Ethiopia selected issues”, IMF country Report, 13(309), New York, 2013.

[12] N. Joseph, "Motivational Factors Relating to Entrepreneurial Intention: A Study of Postgraduate Management Students in India", ABAC Journal, 3(1), 2013.

[13] N.F. Krueger and A.L. Carsrud, "Entrepreneurial intentions: applying the theory of planned behavior", Entrepreneurship and Regional Development, 5, 1993, 315-330.

[14] N.F. Krueger, M.D. Reill and A.L. Carsrud, "Competing models of entrepreneurial intentions" Journal of business venturing, 15, 2000, 411-432.

[15] J. Malebana, "Entrepreneurial intentions of South African rural university students: A test of the theory of planned behavior" Journal of Economics and Behavioral Studies, 6(2), 2014, 130.

[16] J.A.Moriano, M. Gorgievski, M. Laguna, U. Stephan and K. Zarafshani, "A cross-cultural approach to understanding the entrepreneurial intention" Journal of Career Development, In press, 2011.

[17] T. Seble, "Ethiopian New Graduates Frustrated by Dimmer Job Prospects", Ezega.com, 2011.

[18] The Federal Democratic Republic of Ethiopia, "National Employment Policy and Strategy of Ethiopia" Addis Ababa, Ethiopia, 2009.

[19] A. Tkachev, and L. Kolvereid, "Self-employment intentions among Russian students", Entrepreneurship and Regional Development, $11,1999,269-80$.

[20] T. Yamane, "Statistics: An Introductory Analysis", in Harper and Row (2), (New York, 1967). 